\title{
Protection of natural resources through a sacred prohibition: The rahui on Rapa iti
}

\section{Christian Ghasarian}

The management of natural resources implies conceptions of ownership and property that provide precious information on the way a society perceives itself. Established moralities on the matter are sometimes sustained by a sacredness that reinforces the values and principles at stake. In the case of ideological and environmental change, the sacred conceptions most of the time adjust to new circumstances and become part of the cultural dynamics. An invisible and superior force, associated with the past and the ancestors, legitimates the new social order. ${ }^{1}$ Therefore, compliance with sacred models can ensure protection in the present life. In this essay, I address how these representations can be mobilised to enforce a new set of rules and a set of associated practices defined as 'good' for the whole community. Interestingly, although in the Polynesian society studied here these representations refer to a pre-European past, they are today expressed through the medium of the adopted Christian religion. This hybrid

1 Nielsen, D., 1999. Three Faces of God. Society, Religion, and the Category of Totality in the Philosophie of Emile Durkheim. Albany: State University of New York. 
situation offers a fascinating example of how, with pragmatic logic, societies combine innovations and continuities to give meaning to their members.

The case study presented here is that of Rapa iti, a small and isolated island in the Austral Archipelago (Tuhaa Pae) in French Polynesia. Located approximately 550 kilometres south-east of the closest island of Raivavae, Rapa iti, which is around $40 \mathrm{~km}^{2}$ with a population of only 500 inhabitants, is the southernmost island in the area. The population's collective management of land and marine resources is unique in French Polynesia as it takes place in a political context in which the French laws are applicable only in theory. In fact, the local society regulates individual and community access to the land and to the sea through two customary councils whose members are respected elders. My research on this island began in 2001 and is focused on understanding how global models and institutions are dealt with and reformulated locally. I approach the local dynamics that take place in terms of 'dialogical processes' ${ }^{2}$ rather than acculturative ones, in which dominant external models would simply be imposed on a social space that integrates them as they are. Cultural and social realities are always a matter of construction, even if sometimes a negotiated one, notably when political and technological powers are at stake.

This essay focuses on the institution of the rahui, which combines different structures of meaning and agencies to deal with the marine environment. ${ }^{3}$ It describes an ancient version of rahui on Rapa iti, before addressing the reasons why it was reinstituted a few decades ago on the island and its current principles and related practices. I then show that this institution is part of a local strategy aimed to deal collectively with ownership - a key issue of everyday life in a small community. Subsequently, I explore how the people of Rapa iti carefully manage this consensual, self-imposed prohibition through a form of moral restraint built on a sense of the sacred a pre-European sacred ideology that engages each socialised individual to consider that any infraction of this prohibition can expose him/ her to both social and supernatural sanctions. The last part relates

2 Bakhtin, M., 1985. The Dialogic Imagination: Four Essays. Austin: University of Texas Press.

3 Giddens, A., 1984. The Constitution of Society. Cambridge: Polity Press. 
local laws to global stakes, and analyses the rahui as an expression of an underlying consensual Rapa project to construct and maintain collective local cohesion.

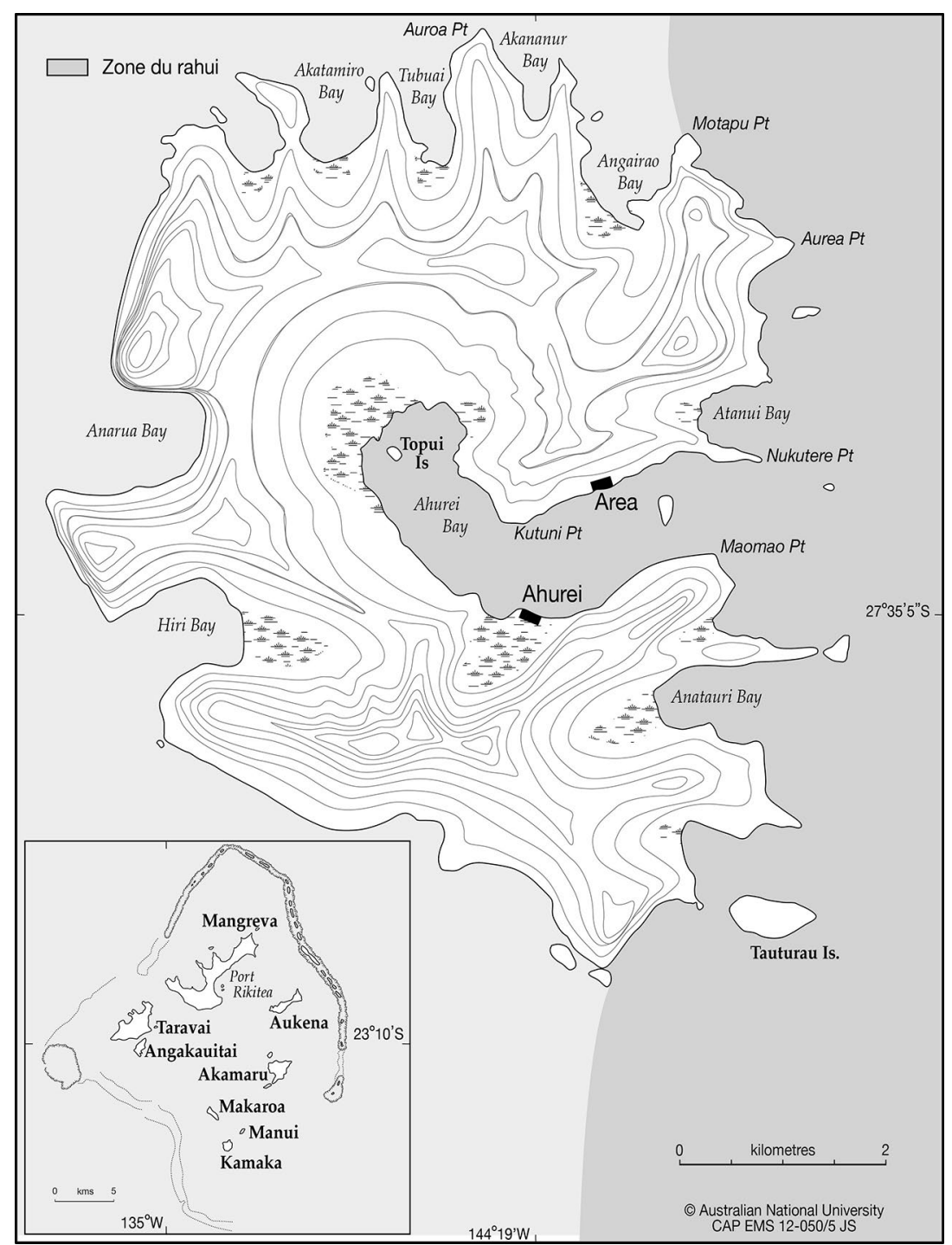

Figure 19: Map of Rapa with the rahui zone

Source: (C) The Australian National University CAP EMS 12-050/5 JS 


\section{Rahui and fishing regulations}

As it is implemented on Rapa iti today, the rahui placed during a defined period on some designated coastal spaces is a prohibition on fishing aimed at allowing the marine fauna to increase for a period without human predation. It is part of a general desire for maintaining natural resources to ensure the community's food supply and, therefore, its survival. However, although there is a rahui on Rapa iti today, rahui is not a Rapa word but a Tahitian one. The Rapa word to qualify prohibitions on some natural resources is $i k i$. Due to lack of historical data, it is difficult to ascertain how the system worked in pre-Christian times. Elders, however, gave me some information about the types of $i k i$ they have known on the island. According to them, there was a sacred dimension to the ancient $i k i$, which was established, for instance, to forbid the gathering of some grey birds of Rapa iti (kea) to allow them to incubate their eggs, to protect a plant (kiekie) that was used for making basket weave (a means for getting money) and, today, to collect mangoes in a given bay of the island only at certain times. All these prohibitions have been implemented to allow resources to grow again in sufficient or larger quantity for a future usage and for its sharing among the population. Interestingly, the substantive $i k i$ was (and still is) also associated with the one of 'danger'. As noted, the term rahui is used on Rapa iti today rather than $i k i$. The word rahui is polysemous and combines meanings such as 'the prohibition', 'the prohibited areas', 'the day of the collective fishing', and 'the products of the fishing in the rahui'.

Before describing the form that the rahui currently takes on Rapa iti, I address the reasons behind its implementation. Interestingly, the project to launch it on the island came from the municipal council (a French institution: Conseil municipal or Tomite oire) almost three decades ago to protect the local marine fauna in a context of technological and social changes. Prior to the setting up of the rahui on Rapa iti, fish were abundant and the fishing modes were not excessively predatory, therefore there was no special prohibition on fishing. In the 1980s, new technologies and fishing techniques were adopted, such as outboard motors, that allowed fishermen to easily catch a large number of fish in a short time. People remember, for instance, that with a simple torch at night they could harvest around 300 lobsters in three hours! New fishing methods (such as using a trap to catch lobsters) 
were then prohibited by the members of the municipal council as they were rapidly depleting some marine food resources. Today, any type of fishing at night is prohibited in the rahui (while, outside the rahui, only fishing underwater is prohibited at night). The prohibition was also extended to fishing with a net everywhere around the island and with an underwater spear gun in some defined areas. Fishing with a harpoon or with a rod, two much less efficient techniques, remained - and still are - authorised everywhere around the island. At the same time that the rahui was set up, an association of fishermen was created to make sure that people respected and understood the new fishing principles.

The existing rahui ban is placed on the 800-metre-wide and twokilometre-long main bay that separates the two villages of the island (Haurei and Area) and on the first three bays on each side of this big bay, extending to the spot called Tematapu in the north and Karapoo koio in the south. Interestingly, the limits are not marked, but are perfectly known by all the fishermen. The system obliges the approximately 80 skilled fishermen of the island to go fishing further away in other bays. The prohibition is at work the whole year, apart from one day, when collective fishing and sharing is organised. Usually, that day is between Christmas and New Year's Eve - two European feasts that have become meaningful on the island. Community events (games, songs, dances and banquets) are organised during that week which marks a special - not only religious - time in local life. In some cases, such as an official government visit, a marriage (which is a collective matter on Rapa iti), or a religious celebration, the rahui can also be reopen. The day to engage the collective fishing is determined by observing the weather in the early morning, and confirming if the sea is peaceful. Everybody, and especially the fishermen, wake up at dawn (usually between $4 \mathrm{am}$ and $5 \mathrm{am}$ ) to be ready to go fishing after watching the quiet sea. Men and women then spontaneously go to the dock where the community gathers for the rahui. The opening of the prohibition of fishing takes place after the singing of a traditional hymn (himene) by the fishermen and people present, followed by a special prayer recited by the pastor of the island who then suspends the rahui prohibition. During this liminal ritual, everybody present humbly stands motionless with heads bent. 
Following the prayer (which takes around five minutes) and the suspension of the sacred prohibition (tatara te rahui), the collective fishing can start for eight hours only, from 6 am to $2 \mathrm{pm}$. All the fishermen must have returned to the village by $2 \mathrm{pm}$ at the latest. With their fishing gear, they leave in small or bigger groups according to the size of the boats, all of them ready to fish in the rahui, the areas that have been, until then, prohibited for fishing. During the authorised time for catching fish, the men ignore discomfort, diving down, coming up to the boat with a fish, diving down and coming up, again and again. Although this continuous fishing is exhausting, the possibility of catching as many fish as one wants in the previously forbidden areas produces an excitement that wipes out the fatigue. Hour after hour, each boat fills up with more and more fish.

As they return to the village (before $2 \mathrm{pm}$ ), the boats are so heavy with fish that they almost sink into the sea. Just after coming to shore, and before the fishermen take the fish out of the boats and return home to rest, the pastor prays again in the company of everybody present on the dock. That second prayer (which also lasts for approximately five minutes) puts an end to the temporary suspension of the rahui and reinstates it (tamau te rahui). From that moment, fishing in the rahui area is prohibited until it is opened again the following year. The fishermen place their catch on the dock, cover it with big green leaves to protect it from flies, and return to their home by foot or by boat. A dozen men who participated to the fishing then take charge of the second part of the rahui day: the distribution of the catch. They first place each type of fish in a specific pile and then create mixed piles of approximately 100 fish.

Two hours later, an animated crowd gathers on the dock as each family sends a 'representative' to get its share. In company of some of their relatives, these delegates patiently wait their turn with plastic bags and/or barrows until they are called, one after another, to get their several kilos of fish; each family getting an amount based on its size. Some families decide to scale the fish they received directly on the shore near the dock while others take it straight home. Some fish will be consumed the same day and the following days, and the remainder will be placed in freezers for later. Some part of it can also be sent in plastic freezer boxes on the next boat to family members (fetii) 
in Tahiti, a practice that is part of the Polynesian system of reciprocity. ${ }^{4}$ The end of the distribution of the rahui to the entire population and the desertion of the dock as night falls marks the end of the rahui. Let us now examine the logic behind that institution.

\section{Ownership and collective cohesion}

The collective dimension of the rahui is palpable and can be related to a larger model of communal management of the island. As mentioned earlier, the use of sea and land on Rapa iti is regulated by the entire community through two customary institutions: the council of the elders and the committee of the fishing. The first one, the Conseil des Sages or Toohitu, implemented by the French administration at the end of the nineteenth century, ceased to be in existence in the mid-twentieth century and was re-established by the municipal council three decades ago. It includes representative members of different cognatic descent groups ( $k o p u$ ) on the island and is aimed at distributing land for houses and cultivation. ${ }^{5}$ The second institution that deals with natural resources is the local fishing association, the Comité des pêches or Tomite taià. This committee is also sometimes called the Tomite rahui as it is also in charge of the implementation of the prohibition to fish in certain areas, which is ritually lifted from time to time. It is composed of eight persons who are elected annually by the population (previous members cannot be re-elected). As with the Toohitu, it was also created by the municipal council when it instituted the rahui.

These two customary institutions work on the basis of local principles. They have an elected president and a revolving membership composed of elders whose moral status is locally acknowledged (taata paari). As I have mentioned, they are both supported by the municipal council and by the entire the population. That significant participation of a French institution - the most important locally - in the insular collective authority on the management of the land and the sea

4 Robineau, C., 1978. 'Réciprocité, redistribution et prestige, chez les Polynésiens des îles de la société'. Journal des Océanistes 61.

5 Hanson, A. \& Ghasarian, C., 2007. 'The land belongs to everyone. The unstable dynamic of unrestricted cognatic descent in Rapa, French Polynesia'. Journal the Polynesian Society 116(1): 59-72. 
informs us about the preponderant role the mayor and the members of the municipal council play in reinforcing local autonomy. In a way, it could be said that the official Rapa representatives to the French administration use the power given to them from outside to empower the insular community in its management of the land and the sea. A new tradition has been invented locally for concrete purposes and has taken a pre-European value that continues to increase in strength in the minds of the people. ${ }^{6}$

The customary collective system of ownership as it has been developed on Rapa iti remains fragile as more and more individualistic outlooks and strategies have developed in recent years. These mostly come from people of Rapa ancestry who are not full-time residents but who come back to the island from time to time to claim land rights, as the system of cognatic unrestricted descent includes them in collective ownership. In the meantime, some residents, wishing to improve their future and that of their close relatives on their own terms, try to appropriate some 'mobile goods' on the land, such as the wild cattle (cows and goats) that roam freely over the hills of the island. They do so by marking the animals they catch in a specific way on their ears. In an identity process that emerges from situations that favour one's own difference, ${ }^{7}$ most local residents denounce these individualistic attitudes and are even more inclined to protect the communal interest.

To get a bigger picture of the situation, I should mention that the cattle are collectively owned and managed by another institution: the Coopérative of Rapa iti. Established in 1928 to collectively manage a dozen cows imported from New Zealand, the Coopérative (which is also in charge of the importation of basic goods such as powdered milk, soap, flour, sugar, petrol and tobacco) has 66 members, one from each family unit (utuafare), whose ancestors decided that the increasing number of wild cattle would be the collective property of all the members of the Coopérative, and therefore of all the population

6 Hobsbawm, R. \& Ranger, T., 1983. The Invention of Tradition. Cambridge University Press; Hanson, A., 1989, 'The making of the Maori: culture invention and its logic'. American Anthropologist 91: 890-902.

7 Barth, F.,1969. Ethnic Groups and Boundaries: The Social Organization of Culture Difference. Bergen: Oslo; London: George Allen \& Unwin. 
of the island at that time. Although some current households do not have a representative member in the Coopérative, everyone still has close relatives who are members by ancestry. ${ }^{8}$

Although it was considerably weakened on the other islands of French Polynesia because of the French code civil, the Polynesian distinction between the right of exploitation and the right of ownership remains operational on Rapa iti. ${ }^{9}$ On the island, collective goods, such as the land and the sea, can be used - and in a way appropriated temporarily but not definitely. The exploitation of the land (for a house and/or a plantation) is of course more durable than that of the sea, on which people just come and go. Through this logic, according to which the main resources of the island can only be temporarily used, individual fishing enclosures (to keep the fish alive in the sea after being caught) are still not allowed today on Rapa iti as that would constitute a private and durable appropriation of the common sea. The policy of the rahui expresses a common desire to collectively manage ocean resources, through the preservation of some areas of the marine ecosystem around the island, but still needs widely agreed principles to be effective. I address these principles in the following section.

\section{A local strategy between social and sacred control}

Elders on the islands have memories of painful periods when food was in short supply. They have also heard of difficult times earlier on in the island's history involving starvation, which sometimes led their ancestors to fight to the death for the limited land and resources available on this small island. In people's minds, regulating the distribution of the land through the Toohitu is a way to maintain the unity of the population in the present day. The control of the usage of the sea derives from the same logic: the sea is considered as a food resource that can become limited and so has to be used with care. By voluntarily preventing themselves from fishing in the areas that are

8 Hanson, A., 1970. Rapan Lifeways. Society and History on a Polynesian Island. Boston: Little, Brown.

9 Ottino, P., 1972. Rangiroa. Parenté étendue, residence et terres dans un atoll polynésien. Paris: Editions Cujas. 
closest to and easiest to access from the villages, local residents allow the fish in these areas to reproduce in number without any threat from human predators, which makes them easy preys in case of urgent need or for special community feasts.

I do have not enough data to say that this contemporary concern about a possible difficult time to come - therefore a sense of life in the future - is something new on Rapa iti, but this clearly sustains the institution of the rahui. My anthropological research on Rapa iti over the last 13 years has revealed that the protection of the island is a recurrent idea that is often explicitly expressed by the population. ${ }^{10}$ The respect for the rahui prohibition is perceived by everybody as a mutual act of responsibility towards the whole community (including past and future generations). The self-imposed rule to not appropriate more land than what is allowed and to not fish in certain marine spaces with certain fishing equipment definitely plays a role in social cohesion - which, as we know, is not a given but a dynamic and constantly challenged process. Being established by the population, the Toohitu and the rahui committee constitute a unifying strength in the local community. Behind them, people imagine and represent themselves through a sense of duty and care for their natural resources. ${ }^{11}$

If the respect for the rahui first takes place in individuals' consciousness, in their constructed sense of morality, the people of Rapa iti have nevertheless developed a social system of control to implement it. In relation to responsibility for one's self (in people's minds and belief systems), this form of control is simply realised by people's watching others' actions and places of fishing. Due to the size of the island, it is rare for a fisherman to go fishing out of sight of other fishermen. Therefore, everybody is potentially obliged to comply with the rules by the simple presence of other people involved in the same sphere of activity. Besides this social control system, fully supported by the municipal council, the Tomite rahui responsible for everything related to fishing (security matters, rescuing of fishermen, and so on) is also supposed to intervene by boat if the rules are broken (including those committed by fishing boats from off the island).

10 Ghasarian, C., 2014. Rapa. Île du bout du monde, île dans le monde. Paris: Demopolis.

11 Anderson, B., 1989. Imagined Communities. Reflections on the Origin and Spread of Nationalism. London: Verso. 
Social sanction, ranging from moral condemnation and the threat of social ostracism to concrete punishment, is always possible when the prohibitions of the rahui are not respected. Everybody remembers for instance what happened around 20 years ago to a family of the village of Area whose son went to fish in the rahui. He was seen - therefore caught in the act - and the mayor of the island at that time (reputed to be quite a tough person) decided with the municipal council to cut off for one week the electricity in his family household. This situation is extreme and, although the possibility of social coercion is present (through the Tomite rahui, for instance), this control system has up to now been only rarely enforced. Nonetheless, elders remember that at the beginning of the implementation of the rahui on the island in the early 1980s, cases of infringement of the rahui could be observed. This is why, a few years after having set up the rahui, the people most willing to have it respected resorted to a strategy to give more strength to this institution: they enhanced respect for the prohibition through giving it a religious dimension. Consequently, the pastor was asked to participate in the rahui by opening and closing it. Apparently, the succeeding pastors on Rapa iti (each one staying on the island for only four years) have enthusiastically endorsed the responsibility to bring God - and the awe that it entails - into the rahui. As one would expect, these pastors have since been among the strongest advocates of that institution.

As it works today, the rahui seeks to prevent transgressions, perpetrated individually or not, through a sacred prohibition. It is sustained by a collective representation of the natural environment as a door to an invisible power of the imperceptible world. The idea of a sacred power beyond oneself and what is visible and tangible is clearly behind the system and the respect for the rahui. The dramatisation of the moment, with public prayers, implicates each individual who is considered to be fully responsible for acting in accordance with what is defined as a common good. As the rahui is about fishing, it concerns only men who, in the local gender division of labour, are the ones who go fishing. The compliance with the ban is mainly based on a selfimposed avoidance of an act that would be perceived as inauspicious if realised. In local conceptions, infringing the prohibition places the individual in a dangerous situation. All the fishermen consider that a problem, an accident or a disease can hit them and their close ones if they fish in the rahui. Collective stories point out the misfortunes that 
have befallen those fishermen suspected of having violated the rahui, for instance, trouble with their motor boats, a situation that prevented them from going fishing on their own for a time.

People also consider that the punishments can be much bigger than such technical damages, as the rahui involves a dimension beyond human understanding. The underlying presence of sacred forces, associated with mana and ancestors supervising their descendants' deeds towards the island and the community, reinforces the deference to the system. Any fishing in the rahui outside its official and temporary opening exposes offenders to social reprobation and supernatural sanction; two strong reasons for local people to comply with the prohibition. In a way, a sense of tapu - and the consequent fear of its violation - is associated with the rahui. Yet, people of Rapa iti do not consider the rahui exactly as a tapu, as it is initiated by a collective decision aimed at dealing with natural resources and it does not have a definitive character that they normally associate with things marked as tapu (like the inconceivable act of moving an ofai fenua, a stone separating the clan land units in the previous land tenure system).

\section{Local laws, global stakes}

I would like to conclude this chapter by viewing Rapa customary institutions from the French legal perspective, as Rapa iti, along with more than 100 other islands, belongs to the political and administrative entity called 'French Polynesia'. With regard to the French jurisdiction, all the islands of French Polynesia (their land and their surrounding sea) are subjected to the same rules. Based on the Roman law, the French code civil does not sustain the idea of the land as collective property, but highlights private rights. Therefore, the customary system of collective management of the land of Rapa iti is a contradiction of French laws. The same can be said about the population's implementation of the rahui prohibition that has no legal validity in French law. As the marine space between the Polynesian Islands is the property of the French state, anybody who is a French citizen - Polynesian or not - can theoretically fish wherever he or she chooses. Therefore, the French jurisdiction makes it legal for non- 
Rapa people - and also for Rapa residents on or off the island (as long as they are French) to fish in the rahui of Rapa iti, even if the islanders themselves have decided not to do it.

A few years ago, a boat from Tahiti came at night to place some traps around the island to harvest big red lobsters. This incident expresses a classic case of cultural-juridical pluralism ${ }^{12}$ and also exemplifies a collision of moralities. A Rapa iti fisherman who happened to be fishing at night saw the Tahitian boat crew placing traps in the rahui. He ran back to the village and informed everybody. A moment later, almost all the able-bodied men of the island were in their boats, removing these traps from the sea. Someone was delegated to go to the Tahitian boat (which had taken anchor some distance from the shore after placing its traps) to tell its captain to come to the harbour of the island the next morning to meet the population. When the captain and its team arrived at the meeting place, the mayor and the Rapa iti fishermen explained to them that they had done something that the islanders do not even allow themselves to do, that is, fishing in their rahui. Having stated that this act was locally forbidden, the Rapa people gave back the empty traps to the Tahitian fishermen. A few weeks later, however, that same boat came back to fish again around the shores of Rapa iti, this time on a Sunday morning, when most people do not go fishing but are in church or stay at home. By good fortune for the islanders, a young boy walking in the hills saw the Tahitian boat furtively fishing in the rahui. Again, the alarm was given and, led by the Tomite rahui, all the able-bodied men of the island jumped into their boats to collect the newly deposited traps. They brought them back to the dock and made a bonfire out of almost all of them, while some were kept as a private 'war treasure'. The Tahitian boat did not dare to come ashore to ask for these traps but instead returned to Tahiti.

It is impossible to say for sure that this Tahitian boat, or any other boat, did not come back again to fish in the rahui, unnoticed by the islanders. Besides, the striking point of this story is that, under the current jurisdiction, any fishing company located in Tahiti and whose interests are external to the island has the right to fish in the places that the people of Rapa iti try to preserve. If the case was brought to court, the current law would be on the side of the Tahitian boat,

12 Bambridge, T. \& Neuffer, P., 2002. 'Pluralisme culturel et juridique: la question foncière en Polynésie française'. Hermès 32/33: 307-16. 
and the judges would probably be very embarrassed to have to justify outsiders' administrative rights as superior to the islanders' moral rights. Fortunately, the fishing company did not dare to go to court to claim the right to fish around the island of Rapa iti, as the risk of highlighting such a sensitive matter was too great. This sad but interesting example shows the contradictions and the collision of global, or at least external, logics with local stakes.

In Appadurai's formulation, these experiences bring the Rapa people face to face with new imaginary and techno scapes that have reinforced a local feeling about external threats. ${ }^{13}$ The imaginary impels residents to find collective ways to protect their island. They thus deal with global processes through constructed cultural answers, ${ }^{14}$ of which the Toohitu and the rahui institutions are among the most important. A form of protectionism of local resources is thus at work on Rapa iti, which also reveals some contemporary dynamics of insular societies. ${ }^{15}$

The rahui system at work on Rapa iti shows how a local community, being primarily concerned for the maintenance of its food resources, thinks and institutes original ways of dealing with its natural properties in relation to possible future emergency needs. Using the same logic, the population of Rapa iti manages the land (to live on and cultivate), the marine fauna and the wild animals that constitute a food resource on the island. It considers that its primary rights in dealing with everyday life should be respected by external institutions and policies. The ancient Polynesian sense of continuity between the land and the sea - two exploitable spaces - is clearly at work here. The term fenua encapsulates all the material dimension of the island: what is on and around it. ${ }^{16}$ It also implicitly refers to the ancestors and to God (Atua) — whose powers are much beyond that of the Christian God, although the formal prayers are Christians - who is constantly mentioned by people when addressing land and sea issues. As agriculture and fishing are long-established activities that insure everyday subsistence on the island, the population is sensitive to the

13 Appadurai, A., 1996. Modernity at Large: Dimensions of Globalization. Minneapolis: University of Minnesota Press.

14 Friedman, J., 1996. Culture Identity and Global Process. London: Sage Publications.

15 Bernardie, N. \& Taglioni, F., 2005. Les dynamiques contemporaines des petits espaces insulaires. Paris: Karthala.

16 Saura, B., 2005. Entre nature et culture. La mise en terre du placenta en Polynésie française. Tahiti: Edition haere Po. 
idea of preservation of its terrestrial and marine environment. This is why the people of the small island of Rapa iti today strongly value a communal relationship with the natural environment, as a condition of their well-being and peace.

The people of Rapa iti value self-management of their resources, based on solidarity and sharing, as their ancestors in all probability also did - although perhaps in a more clannish and exclusive manner (when they did not simply fight against each other). Regulated management of natural resources is possible because the demographic pressure of the population on the environment is not too heavy. Besides, there is little exportation of the local production as the economy is mostly one of subsistence, and the island does not face many external influences (there is no airport and a supply boat arrives every two months). While it is fragile, the system of collective management of the marine fauna described here shows how a small, insular community, remote from the world, values and implements sharing and equity of access to available goods on the land and in the sea. ${ }^{17}$

The rahui on Rapa iti is thus part of a local underlying project aimed at constructing and maintaining a collective local cohesion to face the always possible adversity related to being a very isolated island. It also invites people to be responsible in the protection of the space they have inherited. What makes this rahui policy interesting anthropologically is that it pragmatically combines different dimensions: religion and sacredness, environment and food resources, new techniques and community solidarity, state, territorial and local institutions. Through the geographical distance to Tahiti - and therefore to France and the will to master their insular destiny, the people of Rapa iti are constructing a kind of 'third space' ${ }^{18}$ in which they successfully conjugate customary principles and practices with Western (here French) institutional frameworks. At a time when collective ownership of natural resources is a matter of growing interest in many societies, this forgotten island in a neglected archipelago offers a remarkable model of successful local management of resources in a small community.

17 Doumenge, J-P., 2002. 'Diversité culturelle et constructions des identités collectives outremer'. In D. Wolton et al. (eds), La France et les outre-mers: L'enjeu multiculturel. Hermès 32-33, CNRS Editions.

18 Bhabha, H., 1994. The Location of Culture. New York; London: Routledge. 
This text is taken from The Rahui: Legal pluralism in Polynesian traditional management of resources and territories, edited by Tamatoa Bambridge, published 2016 by ANU Press, The Australian National University, Canberra, Australia. 